\title{
Numerical Simulation of Heat Transfer in Bathtub
}

\author{
Yi Li \\ North China Electric Power University, Baoding 071003, China
}

18331129603@163.com

Keywords: Bathtub; Heat transfer; Matlab; Simulation

\begin{abstract}
We analyze both the heat loss and heat absorption of water in the bathtub, establish the model of water temperature in time and space, by establishing a coordinate system in the shape of rectangular. We use the finite element method to solve the model and take interpolation method thinking about average temperature and water flow rate to find the best strategy to keep water temperature constant without wasting too much water. For example, a $1.7 \mathrm{~m}$ tall man with normal weight has a bath in 40 degrees Celsius for ten minutes in the bathtub of which size is $1.6^{*} 0.8^{*} 0.7 m^{3}$. The best strategy to keep the temperature constant is to let the temperature of the hot water be 42.3 degrees Celsius and the flow rate of the faucet be $0.031 \mathrm{~L} / \mathrm{s}$. Next, we change the shape and the volume of the bathtub, the shape, the volume, the temperature and the motions of the person respectively to simulate the different situation, with the introduction of the average temperature deviation degree, we analyze the change of the results of the model qualitatively. We find three primary elements, which are the volume of the bathtub, the volume of the person the motions of the person. The deviation of volume change of bathtub reaches $23 \%$ and the highest deviation of volume of the person reaches $25 \%$, and the deviation of motions of the person reaches $17 \%$. The deviation of the change of other elements reaches $5 \%$. Therefore, this strategy is more related to the volume of the bathtub, the volume of the person and the motions of the person.
\end{abstract}

\section{Introduction}

The ideal temperature for bath water is about 2 degrees more than the normal body temperature, which is 98.6 degrees Fahrenheit. However, the ideal temperature for bath water varies from person to person. For example, when bathing a baby, the temperature is always lower than the normal temperature when adult takes a bath, because bath water that is too hot can cause burns to the baby‘s skin. Considering that the average body temperature of a man is 98.6 degrees Fahrenheit, the average temperature of bath water should be between 101 degrees Fahrenheit to 106 degrees Fahrenheit. Bathing at home, the bath water once be filled, it will cool down in a short time, like any object at a higher temperature than its surroundings. When people take a hot bath, in order to let the water temperature is neither too high nor too low, remaining in a constant range, so the person adds a constant trickle of hot water from the faucet. When the bath water level reaches the height of overflow drain, excess water will overflow. Owing to the poor control of the water flow rate, it may cause the excessive waste of water. Therefore, we calculate the minimum hot water flow rate to maintain a constant temperature tub, for achieving the purpose of saving water.

In this bath model, at the beginning, we fill the bathtub with constant temperature water. Heat transfer will happen between the water in the bathtub and the outside, including both increase and decrease of the heat. Heat increase is due to the heat from the faucet with hot water. Heat decrease is due to the heat transfer between water in the bathtub and the air, both sides of the bathtub and the air, water and the people. Thus, we analyze and simulate the situation of heat transfer. By using the three dimensional unsteady heat conduction equation, we build a three-dimensional model of the temperature of the bathtub water in space and time, in order to keep the temperature of the water remain unchanged with the least water consumption.

People take a bath in the bathtub, due to the temperature differences between water in bath and bathtub, water and air, water and people. According to the law of heat transfer, the heat of water will dissipate. 
There are three basic heat transfer mechanism of heat transfer, including heat conduction, heat convection and thermal radiation. However, a specific problem which contain or what kind of way of heat transfer, and what is the relationship between these heat transfer ways, all that needs to use the knowledge of heat transfer to judge.

Our model discuss both cooling and absorption of heat of water. In order to achieve the goal of guarantee the constant temperature, we have to balance of heat dissipation and absorption, to find out the best strategy of adding water. The model is established by finite element method, we have carried on the simulation by Matlab. Moreover, we simulate the model, the performance of the simulation clearly shows that, the distribution of water temp in space and time is close to the actual situation.

After the model of the distribution of water temperature in space and time, we analyze several factors that may influence our model, the shape and volume of the tub, the shape/volume/temperature of the person in the bathtub, and the motions made by the person in the bathtub and a bubble bath additive. We find that all these factors make the water temp distribution changed. At the same time, we tackle the extent of dependence on these factors in our strategy. The final analysis is the impact of a bubble bath additive on our model.

\section{Assumptions}

The temperature of the air stays the same, 20 degrees Celsius, it does not change in time and space. The bathroom space is enough big, to ensure that there is enough airflow range. After the air is heated rapidly rising, the new air can immediately add into, so the air temperature can be thought to be constant. The outside environment has relatively small influence on the temperature of the air.

Ignore the heat losses from the faucet in the air. For that, the faucet is close to the bath water, heat loss in the process of water flowing into the bath is relatively small. Ignore the evaporation of water. The evaporation capacity of water is small relative to the total quantity of water, and the humidity is big in the bathroom, so the evaporation of water can be ignored.

The highest temperature of hot water is 60 degrees Celsius, and the peak of faucet hot water flow is $0.5 \mathrm{~L} / \mathrm{s}$. These data is measured in the actual situation. Although some water heater can achieve higher temperature, but too hot water is not suitable to join in the bath. The thickness of bath is the same in any place and only one person take a bath in the bathtub.

\section{Model}

We balance both cooling and heating of water, set temperature boundaries to the model, tackle and simulate the problem, and discuss the influence of some factors changes to the model. First we take one vertex in the bathtub for the origin, establish a three-dimensional coordinate system.

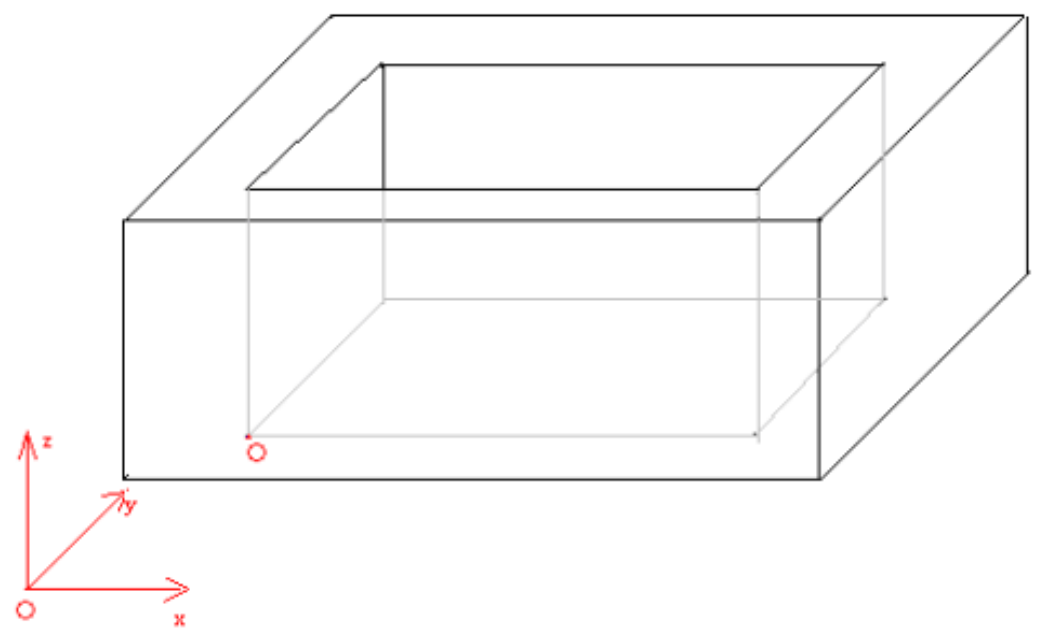

Figure 1. A three-dimensional coordinate system 
Due to water is in the unsteady state, there is a rectangular coordinate system of the three dimensional unsteady heat conduction differential equation with no inner heat source. The water in the bathtub satisfy the unsteady heat transfer process in the third boundary condition.

Water temperature is higher than the air, the heat of water will transfer into air, including heat conduction between water and air. However, the heat convection and the thermal radiation in the bathroom is too small, compared to the heat conduction, then we ignore it.

The heat that the water in the bathtub absorbed mostly comes from the hot water from the faucet, but the process of heat transfer is very complex. For the overall consideration, the inflow of water and the outflow of water is the same, so the total content of water doesn't change. Then, we can consider that the addition of heat is from the faucet. Then heat gradually transfers in the bathtub.

\section{Simulation}

Obviously, the distribution of the temperature of the water in the bathtub is not same, so we adopted the finite element method to solve the problem. We made the latticed partition to the air, the water, the bathtub and the person, setting the boundary conditions and simulated it by MATLAB. We choose the $1.6 * 0.8 * 0.7 \mathrm{~m}^{3}$ cuboid bathtub and choose a $170 \mathrm{~cm}$ person weighing $50 \mathrm{~kg}$. The highest market share of the bathtub material is Acrylic material, so we choose it. After determining these specific parameters, we simulate the temperature field of the water in the bathtub. The average temperature curve in time without adding hot water as follows:

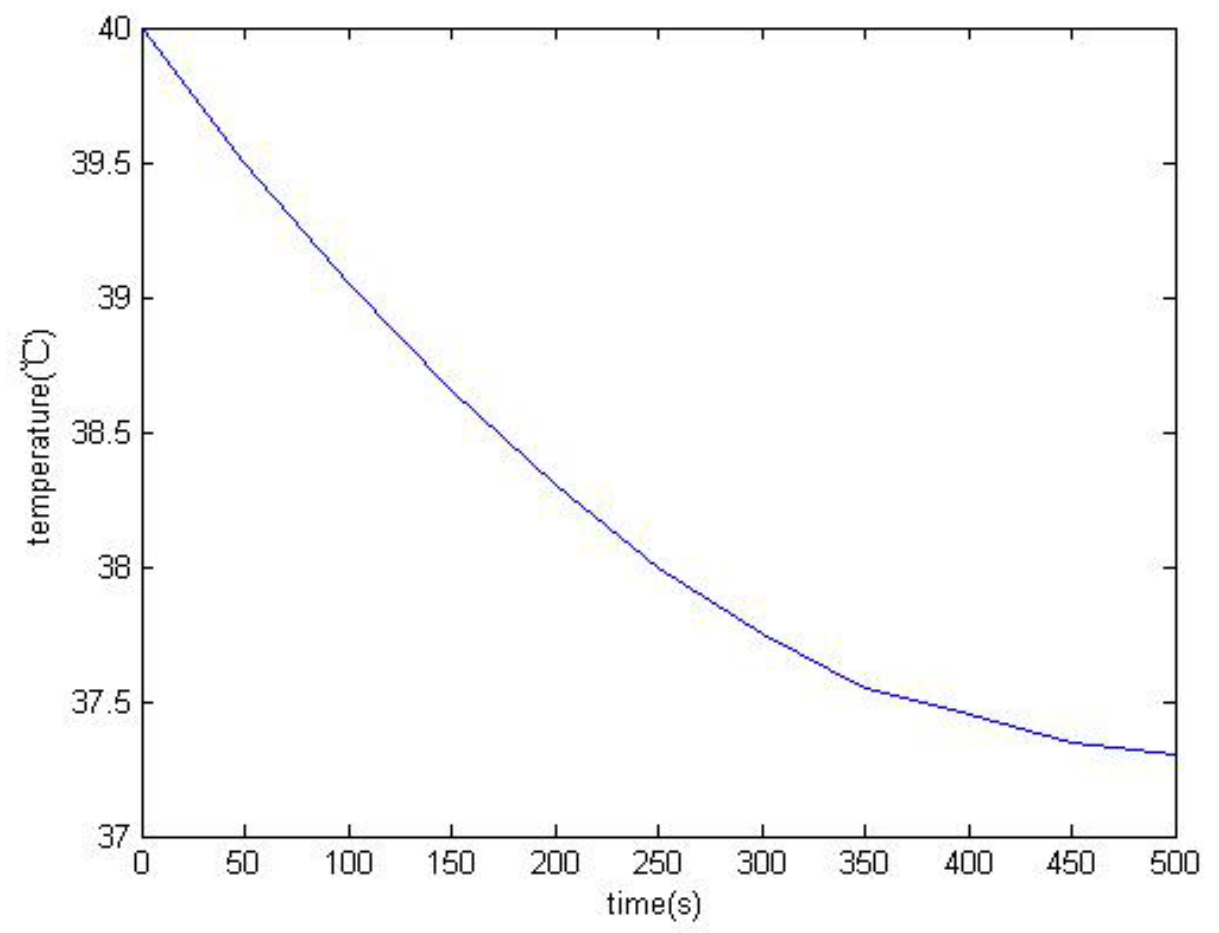

Figure 2. The average temperature drop curve

From the Figure 2, the temperature of the water in the bathtub declines three degrees centigrade in five hundred seconds. In addition, with the dropping of the average temperature, the descent speed of the temperature slows down gradually. To guarantee the comfortable extent of taking a bath, the hot water should be added at the beginning. Through setting the temperature, the rate of hot water flow, the position of the faucet and the time of bath, we can obtain the distribution of the temperature field of water in the whole process. The figure as follows: 


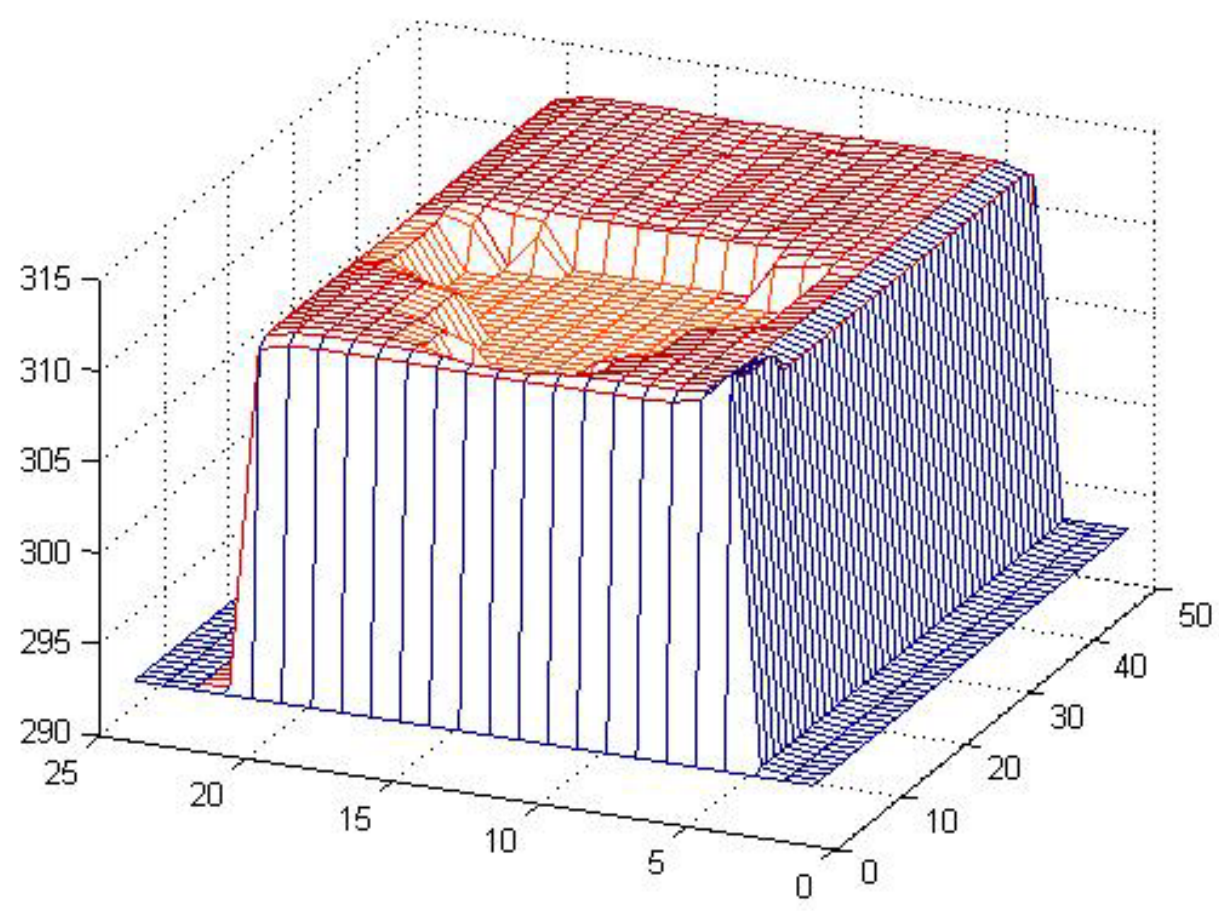

Figure 3. Distribution of temperature field of water

This figure shows the distribution of the temperature fields of liquid level with height of five hundred $\mathrm{mm}$. Because the constant temperature was set by person, there is a low temperature in a small area. Similarly, we can change the value of $\mathrm{z}$ to obtain the distribution of the temperature field's at different height. According to the general temperature of bath water and the rate of hot water from the faucet, we set the temperature in the forty-one to forty-four centigrade with 0.1 step length. Moreover, set the flow rate in the $0.1 \mathrm{~L} / \mathrm{s}$ to $0.7 \mathrm{~L} / \mathrm{s}$ with 0.05 step length. 360 times of simulation of is operated in all. After the interpolation calculation, the surface figure is as follow:

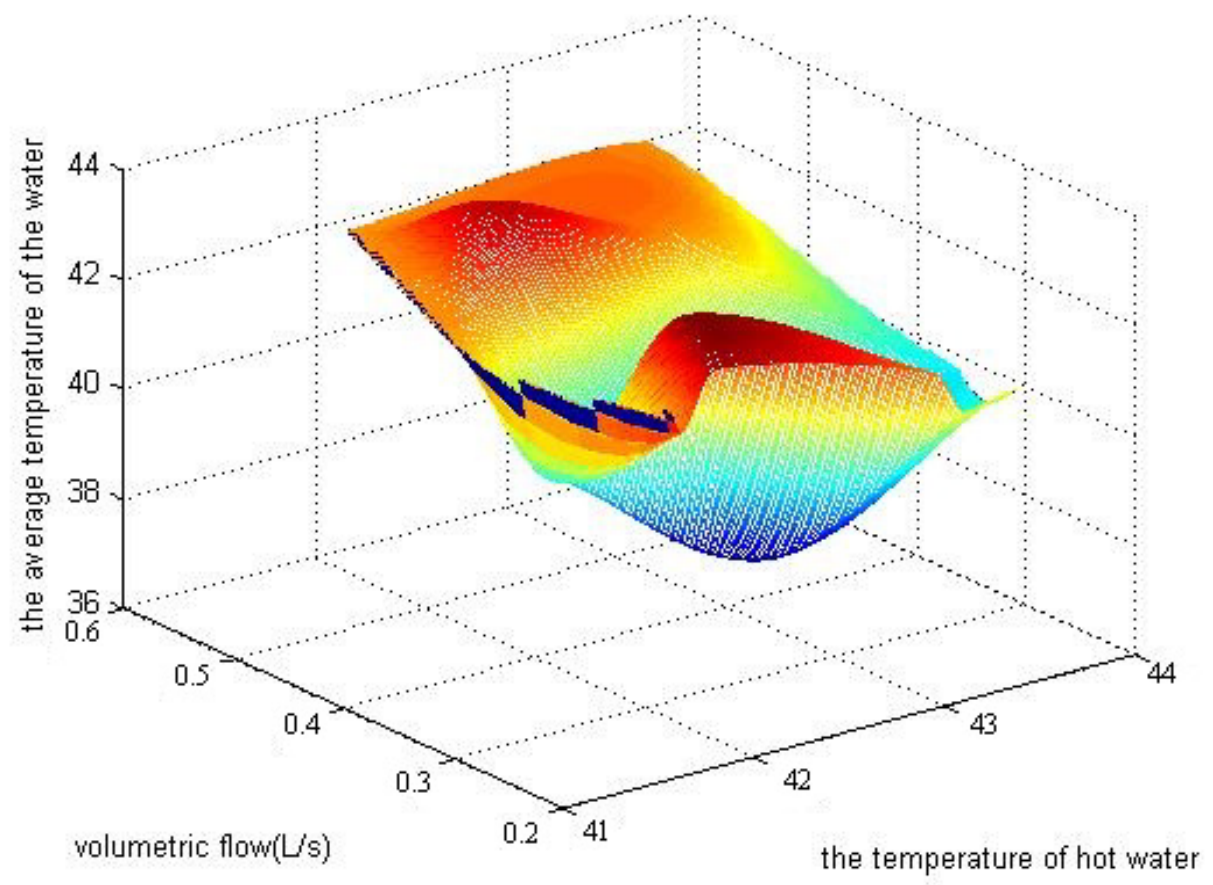

Figure 4. The interpolation curve 


\section{Reference}

[1] Jin-Hai L I, Qin L Z, Cai R H. Control Mathematical Model about the Temperature Diversification of the Hotspring[J]. Journal of Qiongzhou University, 2006.

[2] Nkh A. Determining Natural Convection Heat Transfer Coefficient of Human Body[J]. Frontiers in Heat \& Mass Transfer, 2013, 4(1):940-944.

[3] Sakate M, Yurugi M. Control of thermal cracking in arch abutments constructed in Beppu hotspring region.[J]. Proceedings of the Japan Society of Civil Engineers, 2010.

[4] Beppu R. METAL FIXTURE FOR ADJUSTING SPACE: WO, WO 1993001422 A1[P]. 1993.

[5] Hamamura O. Solar battery module fixture[J]. 2014.

[6] Chen T C, Kam Y C, Lin Y S. Thermal Physiology and Reproductive Phenology of Buergeria japonica (Rhacophoridae) Breeding in a Stream and a Geothermal Hotspring in Taiwan[J]. Zoologicalence, 2016, 18(4):591-596.

[7] Jiang H, Tang M C, Gao X Q. Contribution of Multi-Hotspring Regions over Qinghai-Xizang Plateau to Air Temperature Field[J]. Plateau Meteorology, 2003.

[8] Liu, Dongyan, Luo, et al. Mathematical Model of the Geothermal Water Resources in the South Hot Spring System in Chongqing[J]. Journal of Earth Science, 2005, 16(3):262-267.

[9] Ming L, Li G M, Liao Y, et al. Numerical modeling of geothermal groundwater flow in karst aquifer system in eastern Weibei, Shaanxi Province, China[J]. Science China Earth Sciences, 2007, 50(1):36-41.

[10]Arichi S. The Hotspring Bathing and the Biorhythm[J]. The Journal of Japanese Balneo-Climatological Association, 1974, 37:103-106. 